\title{
Postnatal light alters hypothalamic-pituitary-adrenal axis function and induces a depressive-like phenotype in adult mice
}

DOI:

10.1111/ejn. 13388

\section{Document Version}

Accepted author manuscript

Link to publication record in Manchester Research Explorer

Citation for published version (APA):

Coleman, G., Gigg, J., \& Canal, M. M. (2016). Postnatal light alters hypothalamic-pituitary-adrenal axis function and induces a depressive-like phenotype in adult mice. The European journal of neuroscience, 44(10), 2807-2817. https://doi.org/10.1111/ejn.13388

\section{Published in:}

The European journal of neuroscience

\section{Citing this paper}

Please note that where the full-text provided on Manchester Research Explorer is the Author Accepted Manuscript or Proof version this may differ from the final Published version. If citing, it is advised that you check and use the publisher's definitive version.

\section{General rights}

Copyright and moral rights for the publications made accessible in the Research Explorer are retained by the authors and/or other copyright owners and it is a condition of accessing publications that users recognise and abide by the legal requirements associated with these rights.

\section{Takedown policy}

If you believe that this document breaches copyright please refer to the University of Manchester's Takedown Procedures [http://man.ac.uk/04Y6Bo] or contact uml.scholarlycommunications@manchester.ac.uk providing relevant details, so we can investigate your claim.

\section{OPEN ACCESS}




\section{European Journal of Neuroscience}

\section{Postnatal light alters hypothalamic-pituitary-adrenal (HPA) axis function and induces a depressive-like phenotype in adult mice}

\begin{tabular}{|r|l|}
\hline Journal: & European Journal of Neuroscience \\
\hline Manuscript ID & EJN-2016-07-23857(R).R1 \\
\hline Manuscript Type: & Research Report \\
\hline Date Submitted by the Author: & n/a \\
\hline Complete List of Authors: & $\begin{array}{l}\text { Coleman, Georgia; University of Manchester, Faculty of Life Sciences } \\
\text { Gigg, John; University of Manchester, Faculty of Life Sciences } \\
\text { Canal, Maria; University of Manchester, Faculty of Life Sciences }\end{array}$ \\
\hline Key Words: & $\begin{array}{l}\text { circadian rhythm, corticosterone, constant light, developmental } \\
\text { neurobiology, HPA system }\end{array}$ \\
\hline
\end{tabular}




\section{MANUSCRIPT EJN-2016-07-23857 (R)}

Following the editors' suggestion, we have carefully revised the Discussion section of the manuscript to avoid repetition from the Results section and to eliminate unnecessary detail. We have also corrected some style errors in the Reference list. 
Postnatal light alters hypothalamic-pituitary-adrenal (HPA) axis function and induces a depressive-like phenotype in adult mice

Georgia Coleman, John Gigg, Maria Mercè Canal

Faculty of Life Sciences, University of Manchester, AV Hill Building, Oxford Road, M13 9PT Manchester, UK

Journal section: Behavioural Neuroscience

Running title: Postnatal light and stress

Key words: Circadian rhythm, corticosterone, Arginine vasopressin, corticotrophin-releasing hormone, anxiety, constant light, constant darkness, body temperature

\section{Corresponding author:}

Dr. Maria Canal

Faculty of Life Sciences

University of Manchester

AV Hill Building

Oxford Road,

M13 9PT Manchester, UK

Phone: +44-161-3064219

Fax: +44-161-2753938

e-mail: maria.canal@manchester.ac.uk 


\section{ABSTRACT}

The postnatal light environment that a mouse experiences during the critical first 3 postnatal weeks has long-term effects on both its circadian rhythm output and clock gene expression. Furthermore, data from our lab suggest that postnatal light may also impact the hypothalamic-pituitary-adrenal (HPA) axis, which is a key regulator of stress. To test the effect of postnatal light exposure on adult stress responses and circadian rhythmicity, we raised mice under either 24-h light-dark cycles (LD), constant light (LL) or constant dark (DD) during the first 3 postnatal weeks. After weaning we then exposed all animals to LD cycles (basal conditions), followed by LL (stressed conditions) environments. We examined brain neuropeptide and glucocorticoid receptor (GR) expression, plasma corticosterone concentration rhythm and body temperature rhythm, together with depression- and anxietyrelated behaviour.

Results showed that LL- and DD-raised mice exhibited decreased GR expression in the hippocampus, increased plasma corticosterone concentration at the onset of the dark phase and a depressive phenotype when exposed to LD cycles later in life. Furthermore, LL-raised mice showed increased corticotrophin-releasing hormone mRNA expression in the paraventricular nucleus of the hypothalamus. When exposed to LL as adults, LL-raised mice showed a significant circadian rhythm of plasma corticosterone concentration, together with a shorter period and stronger circadian rhythm of body temperature compared to DD-raised mice.

Taken together, these data suggest that altered postnatal light environments have long-term effects on the HPA axis and the circadian system, which can lead to altered stress responses and a depressive phenotype in adulthood. 


\section{INTRODUCTION}

The hypothalamic-pituitary-adrenal (HPA) system is the final common pathway for the regulation of the stress response (Borrelli, 1998). When an animal perceives a stressor, the paraventricular nucleus of the hypothalamus $(\mathrm{PVN})$ releases corticotrophin-releasing hormone (CRH) and arginine vasopressin (AVP) (Watts et al., 2004). CRH and AVP then synergistically stimulate the production of adrenocorticotropic hormone (ACTH) from the anterior pituitary (Chrousos \& Gold, 1992), which induces the adrenal glands to produce glucocorticoids (corticosterone in rodents, cortisol in humans). The negative feedback of glucocorticoids to the hippocampus and other brain areas inhibits further CRH release (Kim \& Diamond, 2002), thereby shutting down the stress response after the threat has passed. The stress response is strongly influenced by time of day: the suprachiasmatic nucleus of the hypothalamus (SCN), site of the principal circadian pacemaker in mammals (Rusak \& Zucker, 1979), controls the circadian rhythm of glucocorticoid production via efferent AVP containing neurons, which project to the PVN. In addition, the SCN, via the autonomic nervous system, alters adrenal sensitivity to ACTH (Kalsbeek et al., 2012). Rhythmic glucocorticoid release from the adrenal gland into the blood is vital for normal physiological function and dysregulated glucocorticoid rhythms are associated with various human diseases (Chung et al., 2011). Furthermore, long-term activation of the stress system can increase the risk of obesity, heart disease, depression and a variety of other illnesses (Chrousos \& Gold, 1992; Chrousos, 2009; Nicolaides et al., 2014).

Exposure of adult rodents to a constant light (LL) environment produces a loss in the circadian rhythms of locomotor activity, body temperature and plasma corticosterone (Ikeda et al., 2000). If, however, the animals are raised under LL during the critical first 3 postnatal weeks, they will go on to develop circadian rhythms of locomotor activity when exposed to 
LL later in life (Canal-Corretger et al., 2001a; Canal-Corretger et al., 2001b). We have now demonstrated that: 1) the effects of LL-rearing on the circadian system are long-lasting and independent of the dam's rhythmicity (Cambras et al., 1997; Cambras et al., 1998); and 2) the long-term effects of postnatal light experience on circadian behavioural rhythms are due to an imprinting effect of environmental light on the developing SCN, rather than a long-term effect on retinal function (Brooks et al., 2014). Moreover, we have also found that AVP expression in the SCN and PVN is decreased in LL-raised mice compared to mice reared under control light-dark (LD) cycles (Smith \& Canal, 2009).

The aim of this study was to determine the long-term effects of abnormal postnatal light rearing on HPA axis function in adulthood, and the behavioural consequences for the animal. First, we examined neuropeptide and GR expression in the brain, together with the circadian rhythms of plasma corticosterone and body temperature under basal (24-h LD cycles) conditions. We then challenged the animals by exposure to an LL environment and examined their circadian rhythms of plasma corticosterone and body temperature. Finally, the mice underwent a series of tests to assess levels of depression- and anxiety-related behaviour.

\section{MATERIALS AND METHODS}

\section{Animals}

Mice were maintained under a controlled ambient temperature of $21( \pm 2)^{\circ} \mathrm{C}$, with water and food (B\&K Universal, Hull, UK) available ad libitum. Mean light intensity was $330 \mu \mathrm{W} / \mathrm{cm}^{2}$ at cage floor level provided by white LED light, while darkness consisted of no light (0 $\mu \mathrm{W} / \mathrm{cm}^{2}$ ), unless stated otherwise. Cages were changed every fortnight at random times during the day. Infrared goggles were used in the routine maintenance of the animals in the dark. 
All experiments followed the same postnatal protocol: pregnant $\mathrm{C} 57 \mathrm{BL} / 6 \mathrm{~J}$ mice raised in our colony were transferred to either 12:12hr light:dark cycles (LD), constant light (LL) or constant dark (DD) environments 2-3 days before their predicted delivery date (postnatal day (P) 0), to ensure that all pups were born under the intended light conditions. From P0 until P21, the dam and her litter remained undisturbed in the same light condition. At P21, offspring of all experimental groups were weaned; siblings were separated by sex and grouphoused under 24-h LD cycles until the end of the experiment unless otherwise stated. All experimental procedures were conducted in accordance with the United Kingdom Animals (Scientific Procedures) Act 1986 following approval by the local Ethics Committee. All experiments used both male and female mice, unless otherwise stated.

\section{$\operatorname{Exp} 1$}

The aim of the first experiment was to determine the effects of postnatal light environment on adult HPA and circadian function under basal conditions. We examined GR protein and $C r h$ mRNA expression in the paraventricular nucleus of the hypothalamus (PVN), GR expression in the hippocampal formation; the circadian profile of plasma corticosterone concentration and body temperature rhythms under 24-h LD conditions.

\section{Immunohistochemistry}

Adult male and female mice (P50, n=3-7 per group) were culled between Zeitgeber time 4-5 (ZT4-5, where ZT0 corresponds to lights on). ZT4-5 was chosen as a culling time because: a) GR mRNA expression in the Cornu Ammonis 1 (CA1) and Dentate Gyrus (DG) regions of the hippocampal formation has been shown to display a circadian rhythm which peaks between ZT3-7, and b) GR expression in the PVN does not appear to depend on time of day (Herman et al., 1993). Immunohistochemistry was performed as previously described (Smith \& Canal, 2009). The primary antibody was rabbit polyclonal anti-GR (1:5000, Santa Cruz Biotechnology, Dallas, TX, USA). Control sections were also processed without addition of 
either the primary or secondary antibody to test specificity and these showed no staining. Sections were visualized using a microscope (Leica DM2000, Leica Microsystems, Milton Keynes, UK). Digital images were captured, displayed on a computer screen and the number of immune-positive cells manually counted using Image J (v. 1.38, NIH, Bethesda, US). Two researchers blind to the experimental group selected the region of interest as either PVN, CA1 or DG according to the mouse brain atlas $(0.22-3.16 \mathrm{~mm}$ posterior to bregma (Paxinos \& Franklin, 2004)) and counted the number of immune-positive cells in each region of interest (left and right brain, $n=4-6$ sections per animal). Their average was used for further analysis.

Quantitative polymerase chain reaction ( $q P C R$ )

In a separate experiment, we examined the effects of the postnatal light environment on basal Crh mRNA expression within the PVN in adulthood. Male mice ( $\mathrm{n}=6-8$ per group) were raised in LL, LD or DD for the first 3 weeks of life and then exposed to LD from the day of weaning (P21) until the end of the experiment. Adult mice (P50) were culled at ZT16 (4h after lights off), since Crh mRNA expression in the PVN has been shown to display a circadian rhythm peaking during the night (Watts et al., 2004). Culls in the dark were carried out under dim red light $(8.7 \mu \mathrm{W} / \mathrm{cm} 2)$. Flash-frozen $250 \mu \mathrm{m}$ thick sections were cut in a cryostat and mounted on slides. For each mouse, 3 slides containing the PVN were used. The PVN was located using a brain atlas $(0.58-1.06 \mathrm{~mm}$ posterior to bregma (Paxinos \& Franklin, 2004)). 1mm punches containing the PVN were collected into RNAse free tubes then stored at $-80^{\circ} \mathrm{C}$ until extraction. RNA was extracted using RNeasy micro kits (Qiagen, Manchester, UK) following the manufacturer's protocol. Extracted RNA samples were tested on the nanodrop (Thermo Scientific, Warrington, UK) and only samples that had a 260/280 ratio higher than 1.7 were used, which led to three samples being discounted from further analysis. cDNA was obtained by reverse transcription (RT) reaction of the extracted RNA 
samples using the High Capacity RNA-to-cDNA kit available from Applied Biosystems (Life Technologies, Paisley, UK) resulting in a $20 \mu \mathrm{l}$ reaction volume. Non RT controls were run alongside experimental samples. Samples were then stored at $-20^{\circ} \mathrm{C}$ until used.

qPCR experiments were run in triplicate using SYBR Green (Power SYBR Green PCR master mix, Applied Biosystems, Life Technologies, Paisley, UK) on a 7900HT Fast RealTime PCR system machine (Applied Biosystems, Life Technologies, Paisley, UK ). The nucleotide sequences ( $\left.5^{\prime}-3^{\prime}\right)$ of the $C r h$ primers used were:

CTCTCTGGATCTCACCTTCCA (F) and ATCTCCATCAGTTTCCTGTTGCT (R). Melt curve analysis was performed to check that only one product was being amplified and the qPCR product was run on an agarose gel to confirm specificity by showing one band at the expected size. Finally, non-PVN (and non-Crh expressing) samples were run to check the specificity of the Crh primers. Gapdh was quantified as endogenous control. The nucleotide sequences (5'-3') of the Gapdh primers used were: TGTGTCCGTCGTGGATCTGA (F) and CCTGCTTCACCACCTTCTTGA (R). In addition, Gapdh was also used as the normalising reference gene: $\mathrm{Crh}$ gene expression was normalised to that of Gapdh in each sample.

Relative levels of the $C r h$ gene were determined using the 2- $\Delta \Delta \mathrm{Ct}$ method (Schmittgen \& Livak, 2008). Data are expressed as percentage relative to LD raised mice.

\section{$\operatorname{Exp2}$}

Exposure to LL is generally considered stressful, as it increases corticosterone concentration, anxiogenic and depressive-like behaviours in rodents (Bouwknecht et al., 2007; Fonken et al., 2009). Therefore, the aim of this experiment was to test HPA axis and circadian function under stressful conditions in LD and also under LL conditions. Male and female mice were raised under LD, LL or DD conditions from birth until weaning ( $n=5-6$ per group). On the day of weaning (P21), siblings were separated by sex, group-housed and kept under LD until 2 months of age. At around P60, all mice were separated into individual cages and their 
locomotor activity rhythms recorded until the end of the experiment (see locomotor activity recording details below). While still under LD conditions, and at the age of 2.5 months old, all mice underwent a depression-related behavioural test (forced-swim test; see below). They were then transferred to LL. After 2 weeks for acclimatisation, animals were tested for plasma corticosterone levels (circadian profile in LL), followed by anxiety-related behavioural tests a week later (open field, light-dark box and elevated plus-maze; see below) and their body temperature rhythm was then monitored for a further 3 weeks. Depressionrelated and anxiety-related behaviours were recorded by a digital camera mounted on a tripod above the arena and analysed using Ethovision XT 8.5 software (Noldus, Wageningen, Netherlands).

\section{Depression-related behaviour}

We used the forced swim test, a well-established metric for despair and depressive-like behaviour in rodents (Petit-Demouliere et al., 2005). The test commenced between ZT3-4 (34 hours after lights on). Mice were placed individually into a Plexiglas cylinder $(15 \times 18 \mathrm{~cm})$ filled with water $\left(22 \pm 1^{\circ} \mathrm{C}, 7.5 \mathrm{~cm}\right.$ deep $)$ for $6 \mathrm{~min}$, towel dried, and then returned to their home cage. During the test, latency to become immobile and the time spent immobile were noted and used as measures of depressive behaviour. Immobility was defined as a mouse floating in the water and only making movements necessary to maintain its head above the water. Tail tip blood samples were taken pre-swim ( $\mathrm{t}=0 \mathrm{~min})$, immediately after testing $(\mathrm{t}=6$ $\min )$ and 90 minutes after test $\operatorname{start}(t=90 \mathrm{~min})$ to measure the corticosterone response to this stressor.

Anxiety-related behaviour: open field, light-dark box, elevated-plus maze

A series of three behavioural tests were carried out to measure anxiety-like behaviour. Locomotor activity recordings were used to ensure that mice were tested between Circadian time 1-11 (CT1-11, where CT12 corresponds with the onset of activity) for all tests. For all 
tests, mice were first habituated for at least 1 hour to the behavioural testing room and ambient lighting was provided by fluorescent ceiling lights $\left(150 \mu \mathrm{W} / \mathrm{cm}^{2}\right)$. The first test that the mice underwent was the open field, followed by the light-dark box and then elevated plus maze, each separated by an interval of 3 days.

The open field test exploits a mouse's inherent motivation to explore a novel environment versus its preference for being by vertical walls/sides (thigmotaxis) (Simon et al., 1994). A more anxious mouse tends to spend more time near the edge of the arena compared to a less anxious mouse that spends more time in the centre of the arena. The open field arena consisted of a black 5 m Perspex (black 9T30, Gilbert Curry Plastics, Coventry, UK) box which was $50 \mathrm{~cm}$ x $50 \mathrm{~cm}$ wide and $35 \mathrm{~cm}$ high with a white base which provided a good visual contrast between the mouse and the background. Each mouse was placed into the arena in the top left hand corner, facing the wall and behaviour was recorded for 10 minutes using a camera mounted on the ceiling. During testing, the experimenter sat behind a curtain and minimum noise and movement was made. Ethovision XT 7 software (Noldus, Wageningen, Netherlands) was used to automatically track the mouse and generate analysis of the following components of behaviour: distance travelled, time spent in each of the quadrants and time spent in the inner vs outer parts of the arena. After 10 min, mice were removed and the arena was cleaned with $70 \%$ ethanol before the next mouse was tested.

The light-dark box consisted of a rectangular box that was divided into two regions, one light (30 cm length $\times 20 \mathrm{~cm}$ width $\times 25 \mathrm{~cm}$ height) and one dark $(30 \mathrm{~cm}$ length $\times 10 \mathrm{~cm}$ width $\times 25$ cm height). The dark region was constructed of black painted cardboard, whereas the light region was constructed of white Perspex (white 050, Gilbert Curry Plastics, Coventry, UK) and was illuminated by a $60-\mathrm{W}$ light that was 3 feet directly above it. The two chambers were connected by a small opening $(5 \mathrm{~cm}$ height $\mathrm{x} 3 \mathrm{~cm}$ width $)$ that allowed the animals to freely enter either area. The box was cleaned with $70 \%$ ethanol between subjects. For the light-dark 
box test, animals were placed in the light side of the chamber facing the wall and were allowed to move freely between the two compartments for $6 \mathrm{~min}$. The number of entries into and time spent in the two compartments were assessed as indices of anxiety and activity. The elevated plus-maze test was performed on a plus-shaped maze, which was elevated 50 $\mathrm{cm}$ from the floor and consisted of two closed arms $(27 \times 5 \times 30 \mathrm{~cm})$ and two open arms $(27 \times 5 \times 0.2 \mathrm{~cm})$ separated by a central neutral zone $(5 \times 5 \mathrm{~cm})$. A camera above the maze enabled assessment of behaviour. The 10-min elevated plus-maze protocol started by placing the animal in the neutral zone facing an open arm, and the percentage time spent on the open arms, as an indicator of anxiety, was determined by an observer blind to treatment.

\section{Locomotor activity and body temperature recordings and analysis}

In experiment 2, locomotor activity was used to calculate the time of behavioural testing (anxiety-related behavioural tests) and blood sampling (for corticosterone assay) in LL. Recording of mouse locomotor activity was performed as described previously (Smith \& Canal, 2009), using infrared activity meters placed outside of the mouse cage. Data were collected in 15 min bins and stored on a computer. Locomotor activity was recorded continuously from P60 until the end of the experiment.

The circadian rhythms of locomotor activity and corticosterone secretion are regulated through the same neural pathways, which differ from those used in the regulation of body temperature rhythms (Saper et al., 2005). Therefore, we used the circadian rhythm of body temperature as an indicator of circadian clock output independent of the corticosterone rhythm. Body temperature was recorded with surgically-implanted iButtons ${ }^{\circledR}$ (Maxim, San Jose, CA, USA) (Hasselberg et al., 2013). Male mice were anaesthetised by inhalation of 5\% isoflurane which was maintained throughout the surgery. An iButton ${ }^{\circledR}$ was then implanted in the abdominal cavity. After a week of recovery from surgery, body temperature was recorded continuously and data stored in 15 min bins. Body temperature was recorded under both LD 
(Exp1) and LL (Exp2) environments and analysed using E1 Temps@ (A Diez-Noguera, University of Barcelona, Barcelona, Spain). For each experiment, we calculated the following characteristics of the circadian rhythm: period and percentage of variance explained by the highest peak (PV, using the $\mathrm{X}^{2}$-periodogram, an indicator of strength and stability of the rhythm) and daily active phase (alpha) duration and intensity (using the mean waveform). In addition, in Exp1 we calculated psi (phase of entrainment) by calculating the difference in minutes between the onset of darkness and the onset of alpha from the mean waveform, which had previously been smoothed (using a 12-h moving average) to eliminate reactive peaks to light.

\section{Corticosterone assay}

To assess the circadian profile of plasma corticosterone, six tail tip serial blood collections $(20 \mu \mathrm{L})$ were taken every 4 hours in adult mice (3-4 months old) exposed to either LD (Exp1) or LL (Exp2) for a minimum of 2 weeks prior to blood collection. The entire procedure of blood collection, from opening the cabinet housing the mouse cages to putting the blood on ice took 3-4 minutes, thereby avoiding stress-induced increases in corticosterone. In Exp2, locomotor activity recordings were used to determine the time of activity onset (CT12) for each mouse. The blood collection that was taken nearest to this time was assigned to the CT 10-14 group. Five further blood samples were taken, spaced 4 circadian hours apart.

Corticosterone was quantified by Enzyme Immunoassay using a commercially available kit (Cayman chemicals, Michigan, USA) according to the manufacturer's protocol. The crossreactivity of the antibody is: corticosterone 100\%; 11-dehydrocorticosterone, $11 \%$; 11 deoxycorticosterone, $7 \%$; progesterone, $0.31 \%$; cortisol, $0.17 \%$; aldosterone, $0.06 \%$. The detection limit is $30 \mathrm{pg} / \mathrm{mL}$ and the intra- and inter-assay coefficients of variation are $2.8 \%$ and $8.9 \%$, respectively.

\section{Statistical analysis}


Statistical analysis was carried out using SPSS (version 20, IBM Corp., NY, US). ANOVAs were performed for all experiments, with the dependent variables being: GR protein expression, $C r h$ mRNA expression, immobility during the first 2 minutes of the forced-swim test and circadian rhythm of body temperature characteristics (PV, alpha duration and intensity and phase of entrainment in LD). For plasma corticosterone concentration results (circadian profile in LD and LL; response to forced-swim test) repeated measures ANOVAs were used. For all the ANOVAs the independent variables were: postnatal light environment, sex (when appropriate) and ZT/CT/time (when appropriate). For all ANOVAs, interactions between the independent variables were also tested. Post-hoc analyses were performed by means of a Bonferroni test. P values $<0.05$ were considered statistically significant.

Anxiety-related behaviour was first assessed for equal variances using the Levine test and for normality using the Shapiro-Wilk test. Non-normal data that could be normalized by a log transformation was then analysed using a normal ANOVA, otherwise a Kruskall-Wallis test was used.

\section{RESULTS}

\section{Exp 1 - HPA and circadian function under basal conditions}

Expression of stress markers in the brain

We found that the number of GR-positive cells in the PVN was independent of sex and postnatal light environment (mean \pm SD, DD: $119.7 \pm 18.1$ cells $/ \mathrm{mm}^{2}, \mathrm{LD}: 129.6 \pm 14$ cells $/ \mathrm{mm} 2$, LL: $129.3 \pm 15.2$ cells $/ \mathrm{mm}^{2}$ ). In contrast, the number of GR-positive cells in the hippocampal formation was dependent on postnatal light environment $(\mathrm{CA} 1, \mathrm{~F}(2,25)=5.101$, $\mathrm{p}<0.05$; DG, $\mathrm{F}(2,25)=7.379, \mathrm{p}<0.005)$. In CA1, LD-raised mice had significantly higher numbers of GR-positive cells than LL-raised mice ( $\mathrm{p}<0.05$, Fig. 1), while in DG, LD-raised 
mice had higher number of GR-positive cells than DD- and LL-raised mice $(\mathrm{p}<0.005$ and $\mathrm{p}<0.05$, respectively, Fig. 1). No effect of sex was observed.

Postnatal light environment also had a significant effect on basal Crh mRNA in the PVN $(\mathrm{F}(2,36)=3.563, \mathrm{p}<0.05)$, with LL-raised mice showing higher levels than DD-raised mice ( $p<0.05$, Fig. 2). No significant differences between LD-raised mice and LL- or DD-raised mice were found ( $p>0.05$, Fig. 2).

\section{Circadian rhythm of plasma corticosterone in $L D$}

Statistical analysis showed a significant effect of $\operatorname{sex}(F(1,170)=67.125, p<0.001)$, with females showing overall higher plasma corticosterone concentration than males (Fig. 3A,B). In addition, we found a significant interaction between ZT, sex and postnatal light environment $(F(10,170)=2.673, p=0.005)$ : In females, there was only a significant effect of $\mathrm{ZT}(\mathrm{F}(5,80)=21.327, \mathrm{p}<0.001)$, with ZT0 displaying significantly lower plasma corticosterone concentrations than ZT8, ZT12, ZT16 and ZT20 $(\mathrm{p}<0.005)$; ZT4 displaying lower concentrations than ZT8 and ZT20 ( $<<0.005)$; and ZT12 displaying a higher concentration than all other time points $(\mathrm{p}<0.05)$. No effect of postnatal light environment was observed in females. In males, we also found a significant effect of $\mathrm{ZT}(\mathrm{F}(5,90)=40.589$, $\mathrm{p}<0.001$ ), with ZT4 displaying lower plasma corticosterone concentration compared to ZT8, ZT16 and ZT20 $(\mathrm{p}<0.05)$ and ZT12 displaying a higher concentration than all other time points $(\mathrm{p}<0.001)$. Interestingly, we also found a significant interaction between $\mathrm{ZT}$ and postnatal light environment in males $(\mathrm{F}(10,90)=3.318, \mathrm{p}=0.001)$, such that DD- and LLraised animals had higher plasma corticosterone concentration than LD-raised animals only at ZT12 ( $<<0.005$ and $\mathrm{p}<0.05$, respectively, Fig. 3A).

Circadian rhythm output in $L D$

All mice showed significant circadian rhythms of body temperature, entrained to the $24-\mathrm{h}$ LD environment. We found postnatal light environment did not affect any of the variables 
calculated (Table 1), suggesting that the stability, strength, phase of entrainment and active phase characteristics of the circadian rhythm of body temperature were similar amongst the groups.

\section{Exp2 - HPA and circadian function under LL and stressed conditions}

\section{Forced swim test}

As expected, plasma corticosterone significantly changed according to time $(F(2,87)=175.988, p<0.001)$, such that the concentration immediately after the forced swim test $(\mathrm{t}=6 \mathrm{~min})$ was significantly higher than that both prior to testing $(\mathrm{t}=0 \mathrm{~min}, \mathrm{p}<0.001)$ and 90 minutes after the test started ( $\mathrm{t}=90 \mathrm{~min}, \mathrm{p}<0.001$, Fig. 4A, B). Plasma corticosterone concentration at $\mathrm{t}=90$ minutes was also significantly higher than that prior to the test $(\mathrm{t}=0 \mathrm{~min}$, $\mathrm{p}=0.001$, Fig. 4A, B). There was also a significant interaction between sex and time $(\mathrm{F}(2,87)=16.089, \mathrm{p}<0.001)$, such that plasma corticosterone concentration in female mice was higher than that of males at $\mathrm{t}=0$ and 6 minutes $(\mathrm{p}<0.01)$, but not at $\mathrm{t}=90$ minutes (Fig. 4A, B). Postnatal light environment had no effect on plasma corticosterone response to the forced swim test.

We found that sex did not affect the behavioural response of mice to the forced swim test. Postnatal light environment did not have an effect on the latency to become immobile or the time spent immobile in the last 4 minutes of the test, but interestingly, it had a statistically significant effect on immobility duration for the first 2 minutes of testing $(\mathrm{F}(2,29)=5.315$, $\mathrm{p}<0.05)$, with LL-raised mice spending more time immobile than LD-raised mice $(\mathrm{p}<0.05)$.

There was also a trend for DD-raised mice to spend more time immobile than LD-raised mice $(\mathrm{p}=0.052$, Fig. $4 \mathrm{C})$.

Circadian rhythm of plasma corticosterone concentration in $L L$

We found a significant effect of $\operatorname{sex}(F(1,158)=37.484, p<0.001)$, with females showing overall higher plasma corticosterone concentration than males (Fig. 3C, D). In addition, we 
found a significant interaction between postnatal light environment and CT

$(\mathrm{F}(10,158)=2.363, \mathrm{p}<0.05)$ : in LL-raised mice, plasma corticosterone values at CT2-6 were higher than at CT14-18, CT18-22 (p $\leq 0.001)$ and CT22-2, CT6-10 $(p<0.05$, Fig. 3C, D). There were no significant effects of CT on LD- and DD-raised mice.

\section{Anxiety-related behaviour in $L L$}

General activity in the open field arena was measured, including distance moved and velocity. None of these appeared to be dependent on postnatal light experience or sex (Table 2). Time spent in the inner and outer areas of the arena was also measured, as increased time spent in the outer portion of the arena, closer to the walls (thigmotaxis) indicates a more anxious state (Simon et al., 1994). Although all mice spent more time in the outer zone compared to the inner zone, the time spent in each of these areas was not dependent on either postnatal light or sex (Table 2).

Similarly to the open field arena, there was no significant effect of postnatal light or sex on distance travelled or velocity in the light-dark box test (Table 2). Preference for the dark zone is suggestive of a more anxious phenotype. However, the time spent in the dark zone was independent on postnatal light and sex. Similarly, the time spent in the light zone was also independent on postnatal light and sex. On the other hand, the time spent in the entry zone, which is the area between the light and dark zones, was dependent on postnatal light $(\mathrm{F}(2,28)=4.802, \mathrm{p}<0.05)$, with DD-raised mice spending more time in this area than the LDraised mice $(\mathrm{p}<0.05$; Table 2$)$.

In line with previous tests, we found no effect of postnatal light environment or sex on distance travelled or velocity in the elevated plus-maze test (Table 2). Moreover, the time spent in open and closed arms was not affected by postnatal light or sex. Finally, duration of time spent in the centre zone, which is where the mouse is first placed in the arena and is 
neither an open nor closed arm, was also measured. We found no effect of postnatal light, but males spent significantly more time here than females $(F(1,27)=7.483, p<0.05$; Table 2$)$.

\section{Circadian rhythm output in $L L$}

Upon transfer to LL, body temperature rhythms all free-ran with a period (tau) longer than 24 hours and all mice maintained a circadian rhythm throughout the LL stage (Fig. 5). We found a significant effect of postnatal light environment on Tau (free-running period, $\mathrm{F}(2,11)=14.670, \mathrm{p}=0.001)$ and $\mathrm{PV}(\mathrm{F}(2,11)=14.384, \mathrm{p}=0.001)$. Post-hoc analyses demonstrated that Tau was longer in the DD- compared to the LD- and LL-raised mice ( $p<0.005$ in both cases). We also found that LL-raised mice had stronger rhythms than LDand DD-raised mice, as demonstrated by having higher PV ( $p<0.05$ and $\mathrm{p}=0.001$, respectively). Finally, no statistically significant effect of postnatal light environment on active phase characteristics (duration and intensity) was found: alpha duration, DD (50.13 $\pm 0.78 \%)$, LD (51.82 $\pm 2.25 \%)$, LL (50.65 $\pm 1.72 \%) ;$ alpha intensity, DD (50.44 \pm 0.48 $\%), \operatorname{LD}(52.09 \pm 2.19 \%)$, LL $(51.31 \pm 1.45 \%)$.

\section{DISCUSSION}

The aim of this study was to determine the long-term effects of abnormal postnatal light environments on HPA axis function. We found that, compared to LD-raised mice, both LLand DD-raised mice showed decreased GR expression in the DG and increased plasma corticosterone concentration at ZT12 when exposed to LD cycles later in life, together with a tendency to depressive-like but not anxiety-like behaviour in adulthood. Furthermore, some of these effects were dependent on the animal's sex. When exposed to LL later in life, and in contrast to DD-raised mice, LL-raised mice of both sexes showed a significant rhythm of plasma corticosterone concentration as well as a shorter period and stronger circadian rhythm of body temperature. 


\section{HPA function under basal (LD) conditions}

The higher levels of $\mathrm{Crh}$ mRNA expression in the PVN in LL-compared to DD-raised mice that we found in this study could be explained, on the one hand, by the lower AVP protein expression levels in the SCN of these mice (Smith \& Canal, 2009), since CRH expression in the PVN is inhibited by AVP neurons in the SCN (Kalsbeek et al., 2012). On the other hand, Crh mRNA synthesis in the hypothalamus, pituitary and hippocampus is inhibited by GR input (Kloet et al., 1998; Kim \& Diamond, 2002) and we found that GR expression in the CA1 and DG regions of the hippocampal formation was decreased in LL- compared to LDraised mice. Taken together, these results suggest a mechanism whereby an overall decrease in AVP and GR expression in the LL-raised mice may allow for an increase in $C r h$ mRNA expression in the PVN. Moreover, similar changes in CRH and GR expression to those of LL-raised mice have been found in the brain of adult rats that were exposed to maternal separation protocols during the postnatal period (Plotsky \& Meaney, 1993; Ladd et al., 2000; Liu et al., 2000), suggesting that LL-rearing may be considered a stressful early-life event. In line with published literature (Moore \& Eichler, 1972), we found that the peak of the circadian rhythm of plasma corticosterone concentration occurred at the onset of activity (ZT12), whereas the trough was at the onset of the resting phase (ZT0-4). This anticipatory surge of corticosterone before waking is thought to prepare an organism for the physiological demands of the active phase by increasing energy availability and alertness (Kalsbeek et al., 2012). Interestingly, we found a significant effect of postnatal light at the corticosterone peak time (ZT12) in males, with LL- and DD-raised mice showing higher plasma concentration than LD-raised mice. The fact that increased corticosterone levels are only observed at one time point suggests a different circadian regulation of the corticosterone rhythm, probably due to an alteration in circadian pacemaker function. This is supported by differences in circadian neuropeptide and clock gene expression in the SCN of LL- and DD-raised mice 
compared to LD-raised mice (Smith \& Canal, 2009; Brooks et al., 2014). Nevertheless, persistent high levels of corticosteroids and circadian alterations in corticosteroid expression have been linked to increased HPA activation (Plotsky \& Meaney, 1993) and can result in alterations in mood and cognition, including depression (Holsboer, 2000; Chrousos, 2009; Linkowski, 2003). Taken together, these data suggest that the persistent increase in corticosterone levels in the LL- and DD-raised mice, even if only at the time of awakening, may lead to depression and/or heightened stress responses later in life.

\section{HPA axis and circadian function under LL and stressed conditions}

Overall plasma corticosterone concentration in the LL stage of the experiment was decreased compared to the LD stage in all animals. These findings do not agree with previous studies in rats that found increased corticosterone under LL (Abílio et al., 1999; Waite et al., 2012), especially in DD-raised animals (Martynhak et al., 2011) and during day time (Park et al., 2013). Moreover, plasma corticosterone concentration is consistently increased in rats exposed to LL for 7, 14 or 21 days, suggesting that this increase is independent of LL exposure duration (Morimoto et al., 1975). In contrast, a study in mice found decreased plasma corticosterone in animals kept in LL (Fonken et al., 2009), suggesting a differential response between the two animal species.

When exposed to LL in adulthood, rats lose their circadian rhythms of locomotor activity, body temperature and plasma corticosterone (Ikeda et al., 2000). Unlike rats, mice will not always become arrhythmic in LL, but their locomotor activity rhythm will weaken significantly (Canal-Corretger et al., 2001a). Nevertheless, LL-raised mice will go on to show a strong circadian rhythm of locomotor activity with a shorter free-running period when exposed to LL later in life, compared to LD- and DD-raised mice (Brooks et al., 2014). The results of our study are in agreement with these findings and demonstrate, for the first time, that LL-raised mice will maintain a circadian rhythm of plasma corticosterone concentration 
when exposed to LL later in life. This is not surprising, as the circadian regulation of locomotor activity and corticosteroid secretion share common neural pathways (Saper et al., 2005). Maintenance of circadian rhythmicity in LL may prove advantageous to LL-raised mice: the circadian rhythm of corticosterone plays a key role in synchronizing subordinate circadian oscillators in peripheral tissues (Balsalobre et al., 2000), whereas flattening of the circadian rhythm of corticosterone alters monoaminergic neurotransmission and metabolism (Dallman et al., 2000). Therefore, in LD- and DD-raised mice, long-term exposure to a LL environment could lead to desynchrony of the circadian peripheral oscillators and a wide range of effects on metabolism and central nervous system function. Interestingly, we found that the peak of the corticosterone rhythm in LL occurred at CT2-6, which is around the nadir in a LD environment. This could be due to a change in the shape of the rhythm under LL conditions. Alternatively, it could be indicative of a significant increase in the nadir corticosterone levels in LL. Mild chronic stress induces an increase in circadian trough corticosteroid concentration in rats and humans, which can facilitate the development of metabolic syndrome (Dallman et al., 2000). Therefore, although LL-raised mice do not become arrhythmic when exposed to a LL environment later in life, it is possible that they still perceive LL as a mild chronic stress.

Lesion studies have shown that circadian rhythms of locomotor activity and corticosteroid secretion are regulated by the ventrolateral subparaventricular zone (SPZ) and the dorsomedial nucleus of the hypothalamus (DMH), while the dorsal SPZ is crucial for controlling the circadian rhythm of body temperature (Saper et al., 2005). Therefore, a dissociation in the regulation of the circadian rhythms of body temperature and locomotor activity could explain why we did not find any differences in the body temperature rhythm in LD between the groups in this study, while differences in PV and active phase duration of the locomotor activity rhythm in LD have been previously described (Smith \& Canal, 2009). 
Interestingly, however, we found that DD-raised mice displayed a long free-running period of body temperature and LL-raised mice had significantly stronger rhythms when exposed to LL later in life, similar to our previous observation of the locomotor activity rhythm (CanalCorretger et al., 2001a; Brooks et al., 2014). Both the ventral and dorsal SPZ, together with the DMH, are heavily innervated by SCN efferent projections (Saper et al., 2005) and we have previously found significant differences in FOS expression in the SPZ and DMH brain regions in response to a light pulse (Brooks et al., 2011), AVP, vasointestinal polypeptide and PER2 clock gene expression in the SCN (Smith \& Canal, 2009; Brooks et al., 2014) in LLversus DD-raised mice. Taken together, these data suggest that, by programming the SCN, the postnatal light environment causes long-term alterations in afferent brain regions, thereby impacting the regulation of physiological and behavioural rhythms.

\section{Depression- and anxiety- related behaviour}

HPA alterations are closely linked to mood disorders, including depression (Bao et al., 2008;

Holsboer, 2000). Therefore, we submitted our mice to a forced swim test and found that, although there were no differences in the corticosterone plasma response to the test between the groups, LL-raised mice spent more time immobile during the first 2 min of the test than LD-raised mice, suggesting a depressive behavioural phenotype. A similar tendency was observed in DD-raised mice. We found, however, no differences in immobility between the groups during the last $4 \mathrm{~min}$ of the test. In the forced swim test, observation interval is a factor that can change the sensitivity of the test (Petit-Demouliere et al., 2005). Independently of the duration, however, the key factor in this test is to determine the time at which the animal first becomes immobile, which can be as short as 70-80 s or longer than $180 \mathrm{~s}$ (Borsini \& Meli, 1988). Therefore, we assert that in our experiment, the initial response of LL- (and probably also DD-) raised mice was to give up swimming and, thus, became rapidly immobile (within the first 2 min of the test). 
We also submitted mice to three different anxiety tests (elevated plus-maze, open field and light-dark box). We found no major differences between the groups in these tests, suggesting that postnatal light experience impacts depression- but not anxiety-related behaviours. These effects differ from those induced by postnatal photoperiod as animals raised under short postnatal photoperiods ( $8 \mathrm{~h}$ light, $16 \mathrm{~h}$ dark) display increased depression- and altered anxiety-like behaviours compared to mice raised under long photoperiods ( $16 \mathrm{~h}$ of light, $8 \mathrm{~h}$ dark) (Toki et al., 2007; Ciarleglio et al., 2011). It is possible, therefore, that not only the quantity (hours of light/day) but also the pattern of light (LD cycles vs. constant conditions) experienced during the postnatal period determines the type and direction of behavioural alterations observed later in life.

\section{Sex differences}

We found that females had higher corticosterone plasma concentration overall compared to males in both LD and LL stages and in response to the forced swim test. This agrees with previous reports showing that females express higher basal levels of corticosterone (Goel et $a l ., 2011)$ and increased response to stress (Renard et al., 2010).

Although we found no sex differences in GR expression in the brain or in depressive- and anxiety-like behaviours in adulthood, we found a subtle sex difference in how postnatal light environment affected plasma corticosterone concentration in LD. Thus, in males only, LLand DD-raised mice had higher plasma corticosterone concentration than LD-raised mice at ZT12. This difference could be explained by changes at the HPA axis level. Indeed, the longterm effects of early life stress may differ between males and females: maternally-separated females have increased $\mathrm{CRH}$ and activated $\mathrm{CRH}$ after a forced swim test, while males show no effects on CRH expression, but decreased AVP compared to controls (Renard et al., 2010). Sex is, therefore, an important factor for early life effects on AVP and CRH, which can result in downstream changes in corticosterone concentrations. 
Plasma corticosterone concentration in females also varies depending on the phase of oestrous cycle. In female rats and mice, the lowest corticosterone concentrations are observed at oestrus, rising progressively to a maximum at proestrus, almost doubling the value at oestrus (Nichols \& Chevins, 1981; Atkinson \& Waddell, 1997). We did not find differences of this magnitude between individuals in our experiments. Although our female mice were probably at different phases of their oestrus cycle when blood samples were taken, the variability that this induced on plasma corticosterone levels appeared to be minimal and importantly, it seemed to affect all groups in a similar manner.

\section{Conclusions}

Similarly to LL-raised mice, we found that DD-raised mice also have increased plasma corticosterone concentration at ZT12 under a LD environment, decreased GR expression in the DG, and a tendency to become immobile faster in the forced swim test compared to LDraised mice. However, unlike LL-raised mice, DD-raised mice do not have decreased GR expression in $\mathrm{CA} 1$ or increased $\mathrm{Crh}$ mRNA expression in the PVN. These results suggest that although DD-rearing may constitute a type of early-life stress, its effects do not appear to be as strong as those of LL-rearing. This conclusion is supported by the finding that, unlike DD, exposure of adult nocturnal rodents to LL: (a) suppresses their circadian output, as indicated by a loss of the circadian rhythms of locomotor activity, body temperature and plasma corticosterone concentration (Ikeda et al., 2000); and (b) acts as a chronic stressor capable of inducing depressive-like behavioural responses (Fonken et al., 2009). Interestingly, the negative effects of continuous light are also observed in diurnal species such as humans; individuals exposed to light at night, such as shift workers, are at increased risk for cardiovascular disorders, cancer, sleep disturbances, circadian rhythm dysfunctions, mood disorders, gastrointestinal and reproductive dysfunction (Foster \& Wulff, 2005). Our data suggest that, although LL-rearing can lead to altered HPA axis function and a depressed 
phenotype in adulthood, it can also exert a protective effect against disruption of circadian rhythms due to LL exposure later in life. This is in line with the match/mismatch hypothesis, which suggests that mild or moderate aversive conditions during development can shape an individual to be optimally adapted to similar conditions later in life (Santarelli et al., 2014). Taken together, our results demonstrate that, on one hand, early light environment shapes the development of both the stress and circadian systems. On the other hand, our data highlight the importance of early light experience in determining the physiological and behavioural responses of an individual to specific light environments in the future, which can ultimately determine the individual's health and wellbeing.

\section{ACKNOWLEDGEMENTS}

This work was supported by funding from the Biotechnology and Biological Sciences Research Council (BBSRC) to MMC. GC was a recipient of a BBSRC PhD Studentship. The authors declare no conflict of interests.

\section{REFERENCES}

Abílio, V.C., Freitas, F.M., Dolnikoff, M.S., Castrucci, A.M.L. \& Filho, R.F. (1999) Effects of continuous exposure to light on behavioral dopaminergic supersensitivity. Biological Psychiatry, 45, 1622-1629.

Atkinson, H. \& Waddell, B. (1997) Circadian variation in basal plasma corticosterone and adrenocorticotropin in the rat: sexual dimorphism and changes across the estrous cycle. Endocrinology, 138, 3842-3848. 
Balsalobre, A., Brown, S.A., Marcacci, L., Tronche, F., Kellendonk, C., Reichardt, H.M., Schütz, G. \& Schibler, U. (2000) Resetting of circadian time in peripheral tissues by glucocorticoid signaling. Science, 289, 2344-2347.

Bao, A.M., Meynen, G. \& Swaab, D.F. (2008) The stress system in depression and neurodegeneration: Focus on the human hypothalamus. Brain Research Reviews, 57, 531553.

Borrelli, E. (1998) A chilled-out knockout. Nature Genetics, 19, 108-109.

Borsini, F. \& Meli, A. (1988) Is the forced swimming test a suitable model for revealing antidepressant activity? Psychopharmacology, 94, 147-160.

Bouwknecht, J.A., Spiga, F., Staub, D.R., Hale, M.W., Shekhar, A. \& Lowry, C.A. (2007)

Differential effects of exposure to low-light or high-light open-field on anxiety-related behaviors: Relationship to c-Fos expression in serotonergic and non-serotonergic neurons in the dorsal raphe nucleus. Brain Research Bulletin, 72, 32-43.

Brooks, E., Patel, D. \& Canal, M.M. (2014) Programming of mice circadian photic responses by postnatal light environment. PLoS ONE, 9, e97160.

Brooks, E., Waters, E., Farrington, L. \& Canal, M. (2011) Differential hypothalamic tyrosine hydroxylase distribution and activation by light in adult mice reared under different light conditions during the suckling period. Brain Structure and Function, 1-14. 
Cambras, T., Canal, M.M., Torres, A., Vilaplana, J. \& Diez-Noguera, A. (1997)

Manifestation of circadian rhythm under constant light depends on lighting conditions during lactation. American Journal of Physiology - Regulatory, Integrative and Comparative Physiology, 272, R1039-R1046.

Cambras, T., Vilaplana, J., Torres, A., Canal, M.M., Casamitjana, N., Campuzano, A. \& Diez-Noguera, A. (1998) Constant bright light (LL) during lactation in rats prevents arhythmicity due to LL. Physiology \& Behavior, 63, 875-882.

Canal-Corretger, M., Vilaplana, J., Cambras, T. \& Diez-Noguera, A. (2001a) Effect of light on the development of the circadian rhythm of motor activity in the mouse. Chronobiology International, 18, 683-696.

Canal-Corretger, M.M., Vilaplana, J., Cambras, T. \& Diez-Noguera, A. (2001b) Functioning of the rat circadian system is modified by light applied in critical postnatal days. American Journal of Physiology - Regulatory, Integrative and Comparative Physiology, 280, R1023R1030.

Chanson, P. \& Salenave, S. (2010) Metabolic syndrome in Cushing's syndrome. Neuroendocrinology, 92, 96-101.

Chrousos, G.P. (2009) Stress and disorders of the stress system. Nature Reviews Endocrinology, 5, 374-381. 
Chrousos, G.P. \& Gold, P.W. (1992) The concepts of stress and stress system disorders:

Overview of physical and behavioral homeostasis. JAMA, 267, 1244-1252.

Chung, S., Son, G.H. \& Kim, K. (2011) Adrenal peripheral oscillator in generating the circadian glucocorticoid rhythm. Annals of the New York Academy of Sciences, 1220, 71 81.

Ciarleglio, C.M., Resuehr, H.E.S. \& McMahon, D.G. (2011) Interactions of the serotonin and circadian systems: nature and nurture in rhythms and blues. Neuroscience, 197, 8-16.

Dallman, M., Akana, S., Bhatnagar, S., Bell, M. \& Strack, A. (2000) Bottomed out: metabolic significance of the circadian trough in glucocorticoid concentrations. International Journal of Obesity and Related Metabolic Disorders, 24, S40-S46.

Fonken, L.K., Finy, M.S., Walton, J.C., Weil, Z.M., Workman, J.L., Ross, J. \& Nelson, R.J. (2009) Influence of light at night on murine anxiety- and depressive-like responses. Behavioural Brain Research, 205, 349-354.

Foster, R.G. \& Wulff, K. (2005) The rhythm of rest and excess. Nature Reviews Neuroscience, 6, 407-414.

Goel, N., Workman, J.L., Lee, T.T., Innala, L. \& Viau, V. (2011) Sex differences in the HPA axis Comprehensive Physiology. John Wiley \& Sons, Inc. 
Harpaz, I., Abutbul, S., Nemirovsky, A., Gal, R., Cohen, H. \& Monsonego, A. (2013)

Chronic exposure to stress predisposes to higher autoimmune susceptibility in C57BL/6 mice: Glucocorticoids as a double-edged sword. European Journal of Immunology, 43, 758769.

Hasselberg, M.J., McMahon, J. \& Parker, K. (2013) The validity, reliability, and utility of the iButton ${ }^{\circledR}$ for measurement of body temperature circadian rhythms in sleep/wake research. Sleep Medicine, 14, 5-11.

Herman, J., Watson, S., Chao, H., Coirini, H. \& McEwen, B. (1993) Diurnal regulation of glucocorticoid receptro and mineralocorticoid receptor mRNAs in rat hippocampus. Molecular and Cellular Neurosciences, 4, 181-190.

Holsboer, F. (2000) The corticosteroid receptor hypothesis of depression. Neuropsychopharmacology, 23, 477-501.

Ikeda, M., Sagara, M. \& Inoué, S. (2000) Continuous exposure to dim illumination uncouples temporal patterns of sleep, body temperature, locomotion and drinking behavior in the rat. Neuroscience Letters, 279, 185-189.

Kalsbeek, A., van der Spek, R., Lei, J., Endert, E., Buijs, R.M. \& Fliers, E. (2012) Circadian rhythms in the hypothalamo-pituitary-adrenal (HPA) axis. Molecular and Cellular Endocrinology, 349, 20-29. 
Kim, J. \& Diamond, D. (2002) The stressed hippocampus, synaptic plasticity and lost memories. Nature Reviews Neuroscience, 3, 453-462.

Kloet, E.R.d., Vreugdenhil, E., Oitzl, M.S. \& Joëls, M. (1998) Brain corticosteroid receptor balance in health and disease. Endocrine Reviews, 19, 269-301.

Ladd, C., Huot, R., Thrivikraman, K., Nemeroff, C., Meaney, M. \& Plotsky, P. (2000) Longterm behavioral and neuroendocrine adaptations to adverse early experience. Progress in Brain Research, 122, 81-103.

Linkowski, P. (2003) Neuroendocrine profiles in mood disorders. International Journal of Neuropsychopharmacology, 6, 191-197.

Liu, D., Diorio, J., Day, J., Francis, D. \& Meaney, M. (2000) Maternal care, hippocampal synaptogenesis and cognitive development in rats. Nature Neuroscience, 3, 799-806.

Martynhak, B.J., Correia, D., Morais, L.H., Araujo, P., Andersen, M.L., Lima, M.M.S., Louzada, F.M. \& Andreatini, R. (2011) Neonatal exposure to constant light prevents anhedonia-like behavior induced by constant light exposure in adulthood. Behavioural Brain Research, 222, 10-14.

Moore, R.Y. \& Eichler, V.B. (1972) Loss of a circadian adrenal corticosterone rhythm following suprachiasmatic lesions in the rat. Brain Research, 42, 201 - 206. 
Nicolaides, N.C., Charmandari, E., Chrousos, G.P. \& Kino, T. (2014) Circadian endocrine rhythms: the hypothalamic-pituitary-adrenal axis and its actions. Annals of the New York Academy of Sciences, 1318, 71-80.

Park, S.Y., Walker, J.J., Johnson, N.W., Zhao, Z., Lightman, S.L. \& Spiga, F. (2013)

Constant light disrupts the circadian rhythm of steroidogenic proteins in the rat adrenal gland. Molecular and Cellular Endocrinology, 371, 114-123.

Paxinos, G. \& Franklin, K. (2004) The mouse brain in stereotaxic coordinates. Academic Press, New York.

Petit-Demouliere, B., Chenu, F. \& Bourin, M. (2005) Forced swimming test in mice: a review of antidepressant activity. Psychopharmacology, 177, 245-255.

Plotsky, P. \& Meaney, M. (1993) Early postnatal experience alters hypothalamic corticotropin-releasing factor (CRF) mRNA, median eminence CRF content and stressinduced release in adult rats. Brain Research. Molecular Brain Research, 18, 195-200.

Renard, G.M., Rivarola, M.A. \& Suárez, M.M. (2010) Gender-dependent effects of early maternal separation and variable chronic stress on vasopressinergic activity and glucocorticoid receptor expression in adult rats. Developmental Neuroscience, 32, 71-80.

Reul, J.M.H.M. \& De Kloet, E.R. (1985) Two receptor systems for corticosterone in rat brain: Microdistribution and differential occupation. Endocrinology, 117, 2505-2511. 
Rusak, B. \& Zucker, I. (1979) Neural regulation of circadian rhythms. Physiological Reviews, 59, 449-526.

Santarelli, S., Lesuis, S.L., Wang, X.-D., Wagner, K.V., Hartmann, J., Labermaier, C., Scharf, S.H., Müller, M.B., Holsboer, F. \& Schmidt, M.V. (2014) Evidence supporting the match/mismatch hypothesis of psychiatric disorders. European Neuropsychopharmacology, 24, 907-918.

Saper, C.B., Lu, J., Chou, T.C. \& Gooley, J. (2005) The hypothalamic integrator for circadian rhythms. Trends in Neurosciences, 28, 152-157.

Sephton, S.E., Sapolsky, R.M., Kraemer, H.C. \& Spiegel, D. (2000) Diurnal cortisol rhythm as a predictor of breast cancer survival. Journal of the National Cancer Institute, 92, 9941000.

Simon, P., Dupuis, R. \& Costentin, J. (1994) Thigmotaxis as an index of anxiety in mice. Influence of dopaminergic transmissions. Behavioural Brain Research, 61, 59-64.

Smith, L. \& Canal, M.M. (2009) Expression of circadian neuropeptides in the hypothalamus of adult mice is affected by postnatal light experience. Journal of Neuroendocrinology, 21, 946-953.

Toki, S., Morinobu, S., Imanaka, A., Yamamoto, S., Yamawaki, S. \& Honma, K.-i. (2007) Importance of early lighting conditions in maternal care by dam as well as anxiety and memory later in life of offspring. European Journal of Neuroscience, 25, 815-829. 
Waite, E.J., McKenna, M., Kershaw, Y., Walker, J.J., Cho, K., Piggins, H.D. \& Lightman, S.L. (2012) Ultradian corticosterone secretion is maintained in the absence of circadian cues. European Journal of Neuroscience, 36, 3142-3150.

Watts, A.G., Tanimura, S. \& Sanchez-Watts, G. (2004) Corticotropin-releasing hormone and arginine vasopressin gene transcription in the hypothalamic paraventricular nucleus of unstressed rats: daily rhythms and their interactions with corticosterone. Endocrinology, 145, $529-540$. 


\section{FIGURE LEGENDS}

Figure 1. Glucocorticoid receptor protein expression in the hippocampus. Glucocorticoid receptor (GR) immunoreactivity in the hippocampus of male and female mice raised in constant darkness (DD), 24-h light-dark cycles (LD) or constant light (LL) postnatally, exposed to an LD environment in adulthood and culled at Zeitgeber Time (ZT) 4-5. (A) Bright field photomicrograph showing GR-immunoreactivity in the CA1 and Dentate Gyrus (DG) regions of the hippocampal formation; D3V, Dorsal Third Ventricle. Scale bar $=500$ $\mu \mathrm{m}$. Inset is a higher magnification photomicrograph of the CA1 region to illustrate cellular immunostaining. Scale bar $=50 \mu \mathrm{m}$. (B) Representative photomicrographs illustrating GR immunostaining of the CA1 and DG regions in male mice. Scale bar $=100 \mu \mathrm{m}$. (C) Number of immune-positive GR cells in CA1. (D) Number of immune-positive GR cells in DG. ${ }^{*} \mathrm{p}<0.05, * * \mathrm{p}<0.005$. Data are presented as average \pm SEM. $(\mathrm{n}=3-7)$.

Figure 2. Crh mRNA expression in the PVN. Relative Corticotrophin-releasing hormone $(\mathrm{Crh})$ mRNA expression in the paraventricular nucleus of the hypothalamus (PVN) of male mice raised in constant darkness (DD), 24-h light-dark cycles (LD) or constant light (LL) postnatally, exposed to an LD environment in adulthood and culled at Zeitgeber Time (ZT) 16. Crh mRNA levels are normalised to GapdH expression and are relative to the LD group. Data are presented as average \pm SEM. $(\mathrm{n}=6-8)$.

Figure 3. Circadian plasma corticosterone profiles. Circadian changes in plasma corticosterone concentration of adult male and female mice raised in constant darkness (DD), 24-h light-dark cycles (LD) or constant light (LL) postnatally and exposed to (A, B) LD and (C, D) LL environments in adulthood. ZT - Zeitgeber Time; CT - Circadian Time. Main statistical effects: in LD and LL, males vs. females ( $<<0.001$, not shown). Significant interactions: in LD and in males, ZT12 vs. all other ZTs ( $<<0.001$, not shown), ZT4 vs. ZT8, ZT16, ZT20 (p<0.05, not shown), and at ZT12 only, LD vs. LL, DD (\#p<0.05); in LD and in 
females, ZT12 vs. all other ZTs (p<0.05, not shown), ZT4 vs. ZT8, ZT20 (p<0.005, not shown), and ZT0 vs. ZT8, ZT16, ZT20 ( $<<0.005$, not shown); in LL and in the LL group only, CT2-6 vs. CT22-2, CT6-10, CT14-18, CT18-22 (*p<0.05). Data are presented as average \pm SEM. $(\mathrm{n}=5-7)$.

Figure 4. Forced swim test. Plasma corticosterone concentration in (A) male and (B) female mice raised in constant darkness (DD), 24-h light-dark cycles (LD) or constant light (LL) postnatally, at time $0 \mathrm{~min}$ (baseline), time $6 \mathrm{~min}$ (immediately following the test) and time 90 min (90 minutes after the start of the test). (C) Time spent immobile in the first 2 min of the test. $\# \mathrm{p}=0.052,{ }^{*} \mathrm{p}<0.05, * * * \mathrm{p} \leq 0.001$. Data are presented as average \pm SEM. $(\mathrm{n}=5-7)$. Figure 5. Circadian rhythm of body temperature in LL. (A) Representative doubleplotted actograms showing body temperature recordings from adult male mice raised in constant darkness (DD), 24-h light-dark cycles (LD) or constant light (LL) postnatally (indicated on top of each actogram) and exposed to LL for 3 weeks in adulthood. In the ordinates, experimental days are represented. (B) Period of the free-running rhythm of body temperature. (C) Percentage of variance (PV) explained by the highest peak in the periodogram, showing strength of the circadian rhythm of body temperature. Significant interaction: in males, differences due to postnatal light environment $\left({ }^{*} \mathrm{p}<0.05,{ }^{* *} \mathrm{p}<0.005\right)$. Data are presented as average \pm SEM. $(n=4-6)$. 


\begin{tabular}{|c|c|c|c|c|}
\cline { 2 - 5 } \multicolumn{1}{c|}{} & PV (\%) & $\begin{array}{c}\text { Alpha } \\
\text { duration } \\
(\%)\end{array}$ & $\begin{array}{c}\text { Alpha } \\
\text { intensity } \\
(\%)\end{array}$ & $\begin{array}{c}\text { Phase of } \\
\text { entrainment } \\
(\mathbf{m i n})\end{array}$ \\
\hline DD & $69.37 \pm 1.81$ & $50.72 \pm 0.71$ & $51.40 \pm 1.02$ & $-3.95 \pm 7.90$ \\
\hline LD & $63.43 \pm 5.15$ & $51.81 \pm 1.29$ & $52.70 \pm 1.24$ & $-22.37 \pm 27.54$ \\
\hline LL & $64.41 \pm 9.32$ & $51.13 \pm 0.69$ & $51.59 \pm 1.03$ & $-5.92 \pm 11.84$ \\
\hline
\end{tabular}

Table 1: Characteristics of the circadian rhythm of body temperature in LD. Male mice raised in constant darkness (DD), 24-h light-dark cycles (LD) or constant light (LL) postnatally were exposed to a $24 \mathrm{~h}-\mathrm{LD}$ environment in adulthood. The following characteristics of the circadian rhythm of body temperature were measured: percentage of variance (PV), duration and intensity of the active phase (alpha) and phase of entrainment. Data are presented as average $\pm \operatorname{SD} .(n=4-6)$. 


\begin{tabular}{|c|c|c|c|c|c|c|c|}
\hline & \multicolumn{3}{|c|}{ Females } & \multicolumn{3}{|c|}{ Males } \\
\hline & & DD & LD & LL & DD & LD & LL \\
\hline \multirow{4}{*}{ 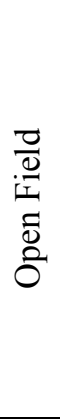 } & $\begin{array}{c}\text { Distance } \\
(\mathrm{m})\end{array}$ & $40.7 \pm 9.8$ & $38.5 \pm 5.3$ & $37.7 \pm 3.1$ & $40.5 \pm 7.8$ & $37.2 \pm 4.6$ & $41.8 \pm 8.9$ \\
\hline & $\begin{array}{c}\text { Velocity } \\
(\mathrm{cm} / \mathrm{s})\end{array}$ & $6.8 \pm 1.6$ & $6.4 \pm 0.9$ & $6.3 \pm 0.5$ & $6.8 \pm 1.3$ & $6.2 \pm 0.8$ & $7.0 \pm 1.5$ \\
\hline & $\begin{array}{l}\text { Time in } \\
\text { inner area } \\
\text { (s) }\end{array}$ & $83.8 \pm 34.0$ & $130.1 \pm 42.3$ & $148.8 \pm 71.0$ & $123.6 \pm 59.0$ & $142.4 \pm 63.2$ & $86.5 \pm 32.2$ \\
\hline & $\begin{array}{c}\text { Time in } \\
\text { outer area } \\
\text { (s) }\end{array}$ & $516.2 \pm 34.0$ & $469.9 \pm 42.3$ & $451.2 \pm 71.0$ & $476.4 \pm 59.0$ & $457.7 \pm 63.2$ & $513.6 \pm 32.2$ \\
\hline \multirow{5}{*}{ 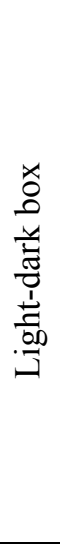 } & $\begin{array}{c}\text { Distance } \\
(\mathrm{m})\end{array}$ & $18.0 \pm 3.4$ & $20.7 \pm 2.6$ & $18.7 \pm 2.4$ & $19.8 \pm 3.6$ & $19.4 \pm 2.4$ & $19.7 \pm 2.6$ \\
\hline & $\begin{array}{c}\text { Velocity } \\
(\mathrm{cm} / \mathrm{s})\end{array}$ & $10.1 \pm 1.1$ & $9.6 \pm 0.8$ & $9.7 \pm 0.7$ & $11.7 \pm 5.6$ & $9.6 \pm 0.6$ & $9.1 \pm 1.1$ \\
\hline & $\begin{array}{l}\text { Time in } \\
\text { light zone } \\
\text { (s) }\end{array}$ & $171.4 \pm 38.5$ & $210.7 \pm 30.8$ & $184.2 \pm 23.3$ & $202.7 \pm 40.3$ & $204.6 \pm 15.2$ & $217.4 \pm 56.3$ \\
\hline & $\begin{array}{l}\text { Time in } \\
\text { dark zone } \\
\text { (s) }\end{array}$ & $174.4 \pm 35.5$ & $136.9 \pm 28.9$ & $163.4 \pm 21.3$ & $135.8 \pm 45.8$ & $142.1 \pm 15.0$ & $130.5 \pm 53.1$ \\
\hline & $\begin{array}{l}\text { Time in } \\
\text { entry zone } \\
\text { (s) }\end{array}$ & $26.3 \pm 4.9 *$ & $18.9 \pm 4.9$ & $24.7 \pm 3.6$ & $34.2 \pm 14.3$ & $23.4 \pm 6.1$ & $21.0 \pm 6.9$ \\
\hline \multirow{5}{*}{ 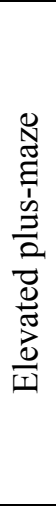 } & $\begin{array}{c}\text { Distance } \\
(\mathrm{m})\end{array}$ & $31.2 \pm 6.2$ & $34.2 \pm 6.6$ & $31.0 \pm 3.1$ & $31.6 \pm 2.7$ & $31.5 \pm 2.9$ & $31.0 \pm 4.3$ \\
\hline & $\begin{array}{l}\text { Velocity } \\
(\mathrm{cm} / \mathrm{s})\end{array}$ & $5.2 \pm 1.1$ & $5.7 \pm 1.1$ & $5.2 \pm 0.5$ & $5.3 \pm 0.4$ & $5.2 \pm 0.5$ & $5.2 \pm 0.7$ \\
\hline & $\begin{array}{c}\text { Total time } \\
\text { in open } \\
\text { arms (s) }\end{array}$ & $66.6 \pm 50.8$ & $78.1 \pm 58.7$ & $89.1 \pm 56.5$ & $67.0 \pm 12.2$ & $98.0 \pm 37.0$ & $54.4 \pm 62.5$ \\
\hline & $\begin{array}{l}\text { Total time } \\
\text { in closed } \\
\text { arms (s) }\end{array}$ & $429.1 \pm 69.3$ & $410.0 \pm 43.5$ & $402.4 \pm 70.7$ & $394.4 \pm 14.2$ & $364.8 \pm 48.9$ & $422.5 \pm 75.6$ \\
\hline & $\begin{array}{l}\text { Total time } \\
\text { in centre }(\mathrm{s})\end{array}$ & $81.1 \pm 19.4$ & $94.4 \pm 20.9$ & $105.6 \pm 24.8$ & $122.3 \pm 12.5 \#$ & $121.0 \pm 23.6 \#$ & $90.5 \pm 27.3 \#$ \\
\hline
\end{tabular}

Table 2: Anxiety-related behavioural tests in LL. Male and female mice raised in constant darkness (DD), 24-h light-dark cycles (LD) or constant light (LL) postnatally and exposed to an LL environment in adulthood, were submitted to three different anxiety-related tests: open field, light-dark box and elevated plus-maze. ${ }^{*} \mathrm{p}<0.05$ DD vs. LD, $\# \mathrm{p}<0.05$ males vs. females. Data are presented as average $\pm \operatorname{SD} .(n=5-6)$. 

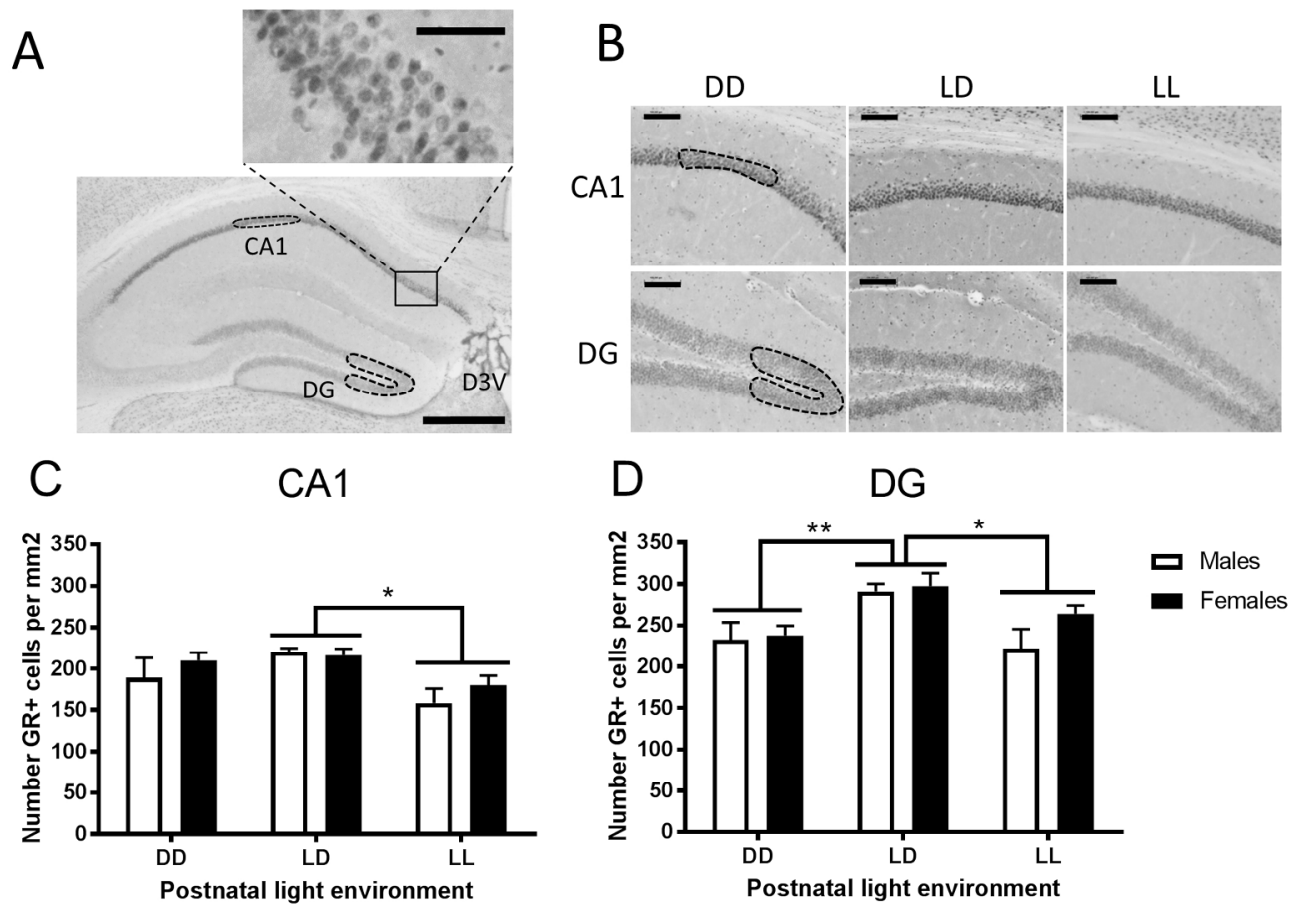

Figure 1. Glucocorticoid receptor protein expression in the hippocampus. Glucocorticoid receptor (GR) immunoreactivity in the hippocampus of male and female mice raised in constant darkness (DD), 24-h lightdark cycles (LD) or constant light (LL) postnatally, exposed to an LD environment in adulthood and culled at Zeitgeber Time (ZT) 4-5. (A) Bright field photomicrograph showing GR-immunoreactivity in the CA1 and Dentate Gyrus (DG) regions of the hippocampal formation; D3V, Dorsal Third Ventricle. Scale bar $=500 \mu \mathrm{m}$.

Inset is a higher magnification photomicrograph of the CA1 region to illustrate cellular immunostaining. Scale bar $=50 \mu \mathrm{m}$. (B) Representative photomicrographs illustrating GR immunostaining of the CA1 and DG regions in male mice. Scale bar $=100 \mu \mathrm{m}$. (C) Number of immune-positive GR cells in CA1. (D) Number of immune-positive GR cells in DG. ${ }^{*} p<0.05, * * p<0.005$. Data are presented as average \pm SEM. $(n=3-7)$.

$$
188 \times 131 \mathrm{~mm}(300 \times 300 \text { DPI })
$$




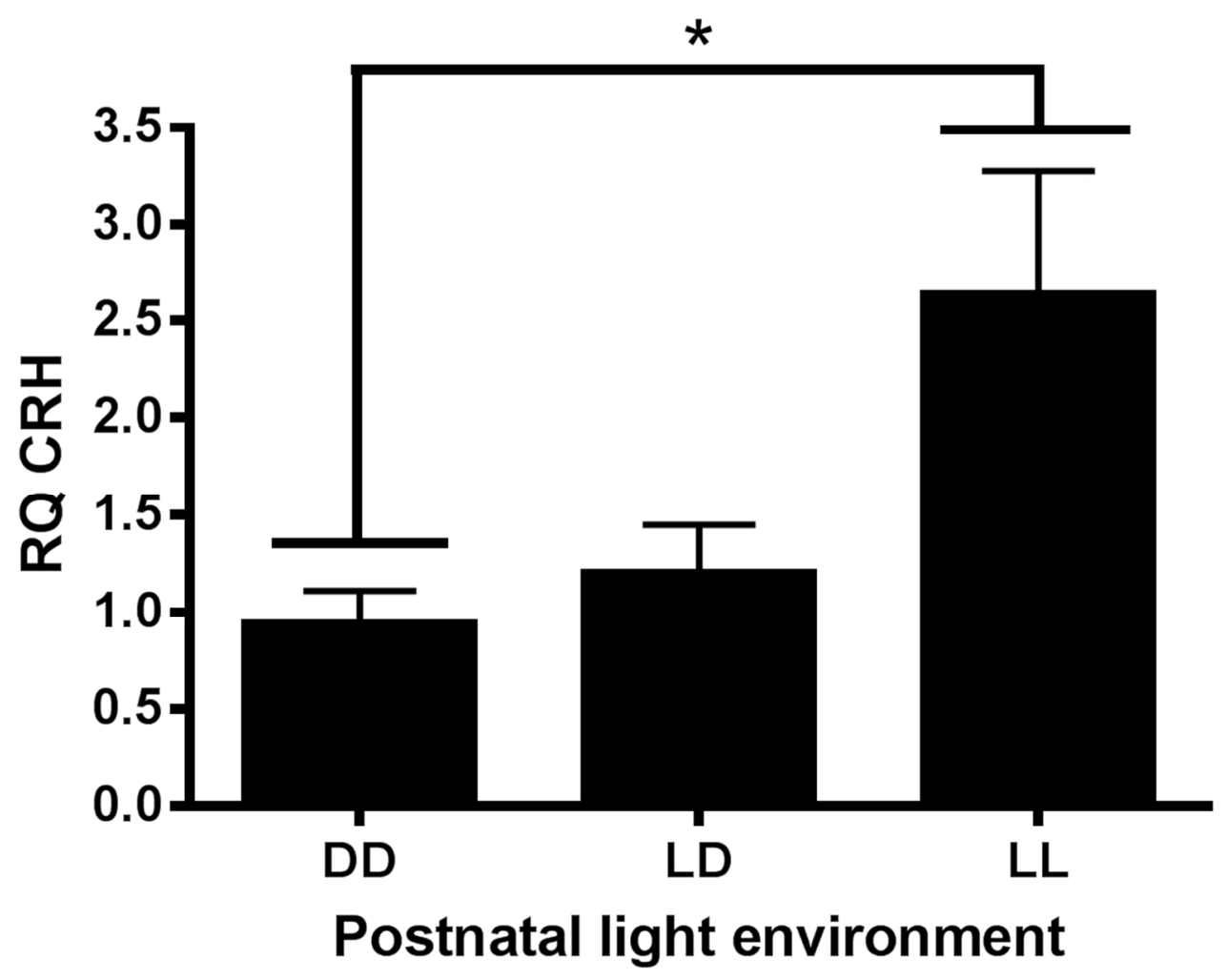

Figure 2. Crh mRNA expression in the PVN. Relative Corticotrophin-releasing hormone (Crh) mRNA expression in the paraventricular nucleus of the hypothalamus (PVN) of male mice raised in constant darkness (DD), 24-h light-dark cycles (LD) or constant light (LL) postnatally, exposed to an LD environment in adulthood and culled at Zeitgeber Time (ZT) 16. Crh mRNA levels are normalised to GapdH expression and are relative to the LD group. Data are presented as average \pm SEM. $(n=6-8)$.

$92 \times 72 \mathrm{~mm}(300 \times 300$ DPI $)$ 

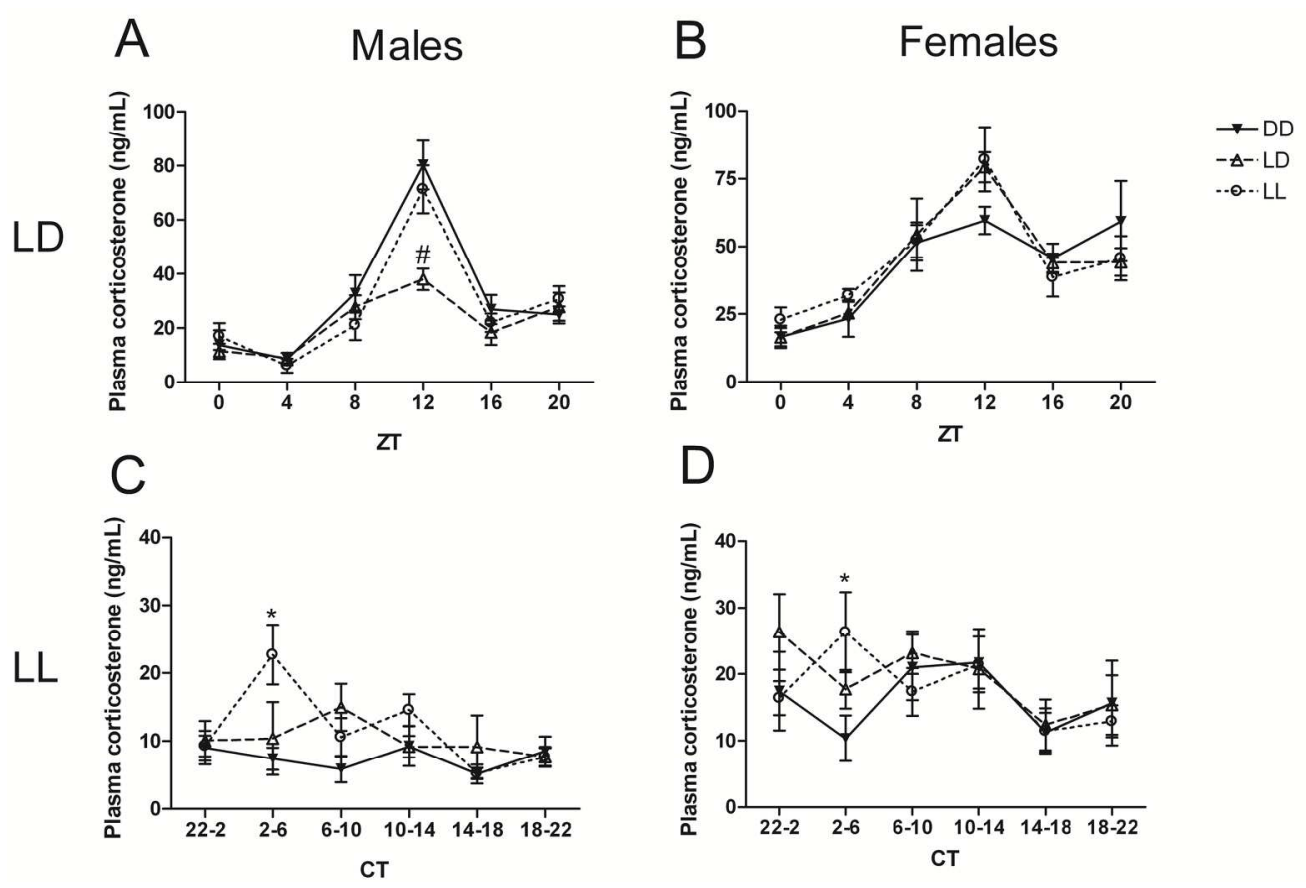

Figure 3. Circadian plasma corticosterone profiles. Circadian changes in plasma corticosterone concentration of adult male and female mice raised in constant darkness (DD), 24-h light-dark cycles (LD) or constant light (LL) postnatally and exposed to (A, B) LD and (C, D) LL environments in adulthood. ZT - Zeitgeber Time; CT - Circadian Time. Main statistical effects: in LD and LL, males vs. females ( $p<0.001$, not shown). Significant interactions: in LD and in males, ZT12 vs. all other ZTs ( $<<0.001$, not shown), ZT4 vs. ZT8, ZT16, ZT20 ( $p<0.05$, not shown), and at ZT12 only, LD vs. LL, DD (\#p<0.05); in LD and in females, ZT12 vs. all other ZTs ( $p<0.05$, not shown), ZT4 vs. ZT8, ZT20 ( $p<0.005$, not shown), and ZT0 vs. ZT8, ZT16, ZT20 ( $p<0.005$, not shown); in LL and in the LL group only, CT2-6 vs. CT22-2, CT6-10, CT14-18, CT18-22 $(* p<0.05)$. Data are presented as average \pm SEM. $(n=5-7)$. 

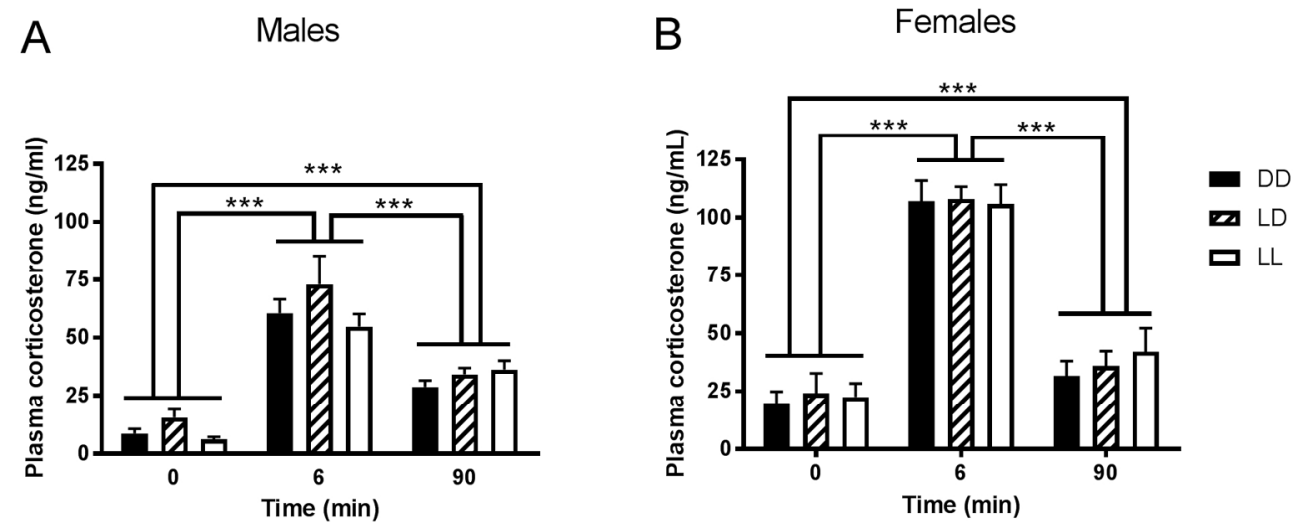

C Immobility first 2 minutes

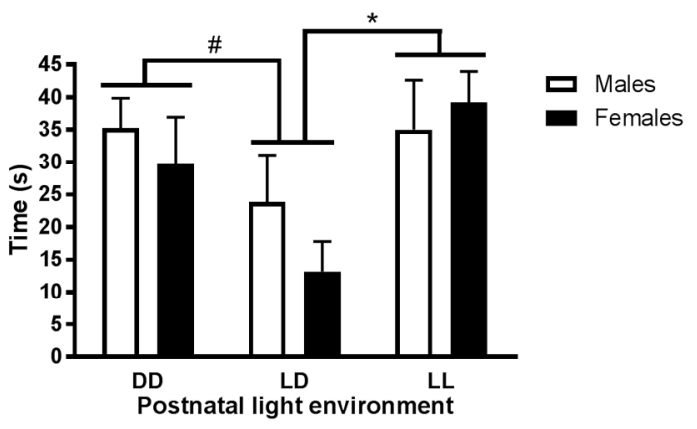

Figure 4. Forced swim test. Plasma corticosterone concentration in (A) male and (B) female mice raised in constant darkness (DD), 24-h light-dark cycles (LD) or constant light (LL) postnatally, at time 0 min (baseline), time 6 min (immediately following the test) and time 90 min (90 minutes after the start of the test). (C) Time spent immobile in the first 2 min of the test. $\# p=0.052, * p<0.05, * * * p \leq 0.001$. Data are presented as average \pm SEM. $(n=5-7)$. 

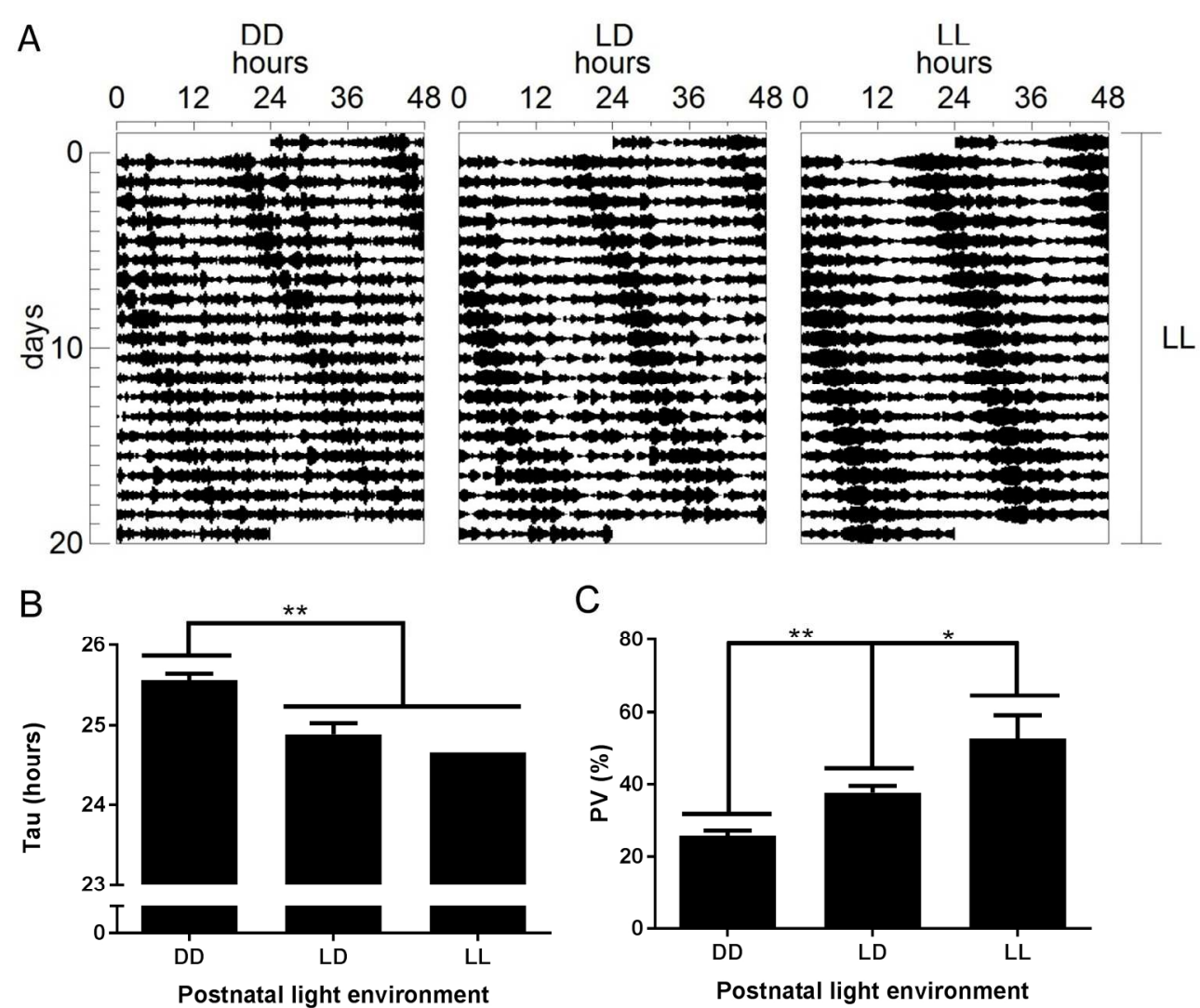

C

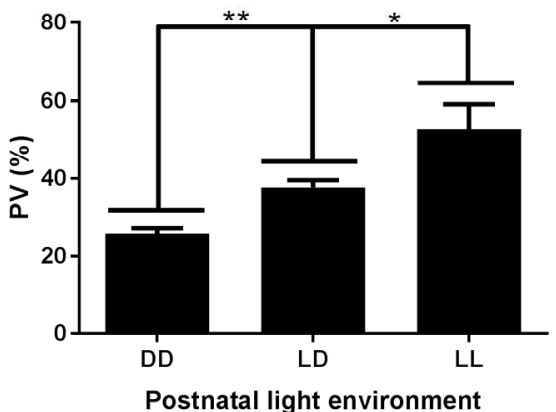

Figure 5. Circadian rhythm of body temperature in LL. (A) Representative double-plotted actograms showing body temperature recordings from adult male mice raised in constant darkness (DD), 24-h light-dark cycles (LD) or constant light (LL) postnatally (indicated on top of each actogram) and exposed to LL for 3 weeks in adulthood. In the ordinates, experimental days are represented. (B) Period of the free-running rhythm of

body temperature. (C) Percentage of variance (PV) explained by the highest peak in the periodogram, showing strength of the circadian rhythm of body temperature. Significant interaction: in males, differences due to postnatal light environment $(* p<0.05, * * p<0.005)$. Data are presented as average \pm SEM. $(n=4-6)$. 
Postnatal light experience has imprinting effects on clock genes and circadian behaviour. In addition to these, here we demonstrate that early light environment can also shape the development of the HPA axis, which can lead to altered stress responses and a depressive phenotype in adulthood. 

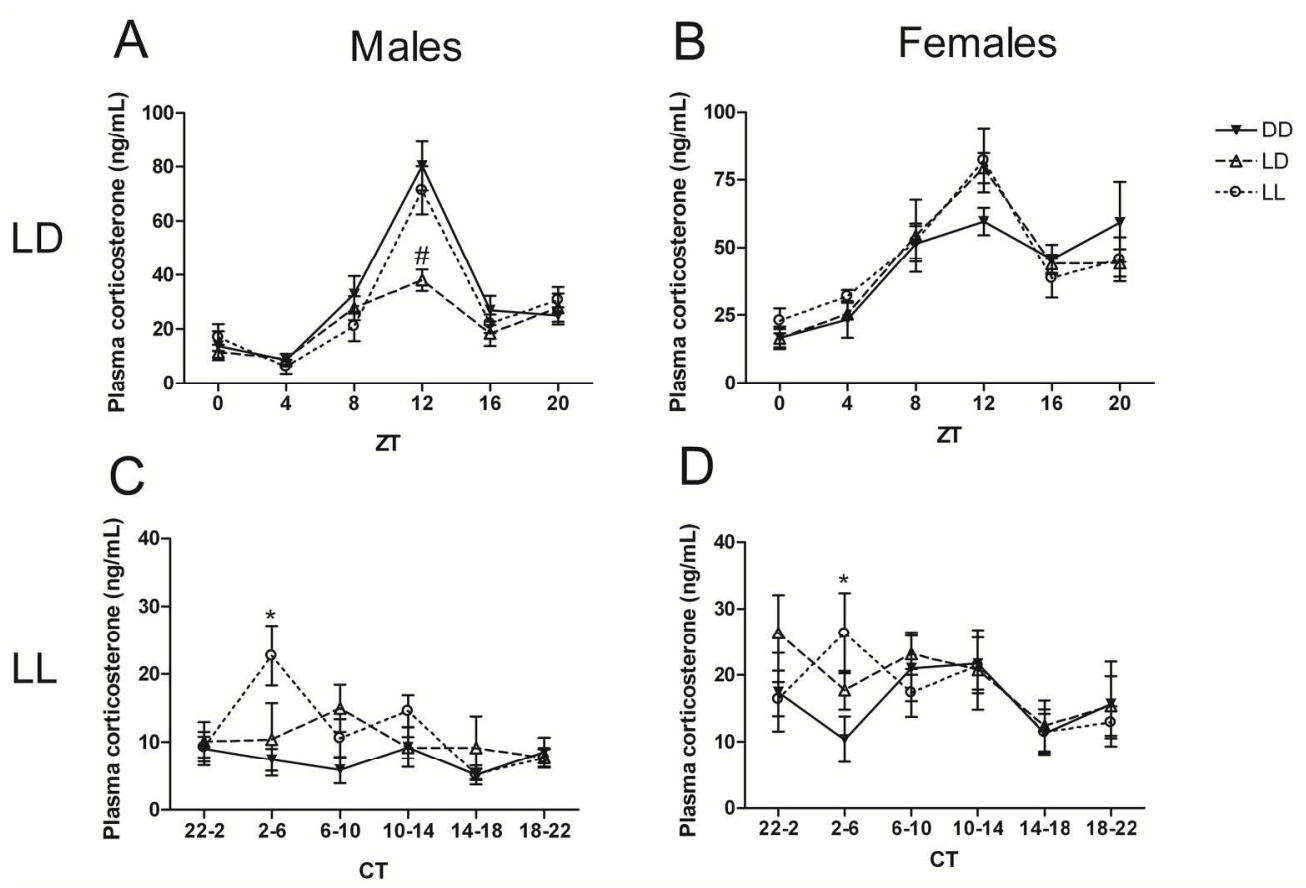

Circadian changes in plasma corticosterone concentration of adult male and female mice raised in constant darkness (DD), 24-h light-dark cycles (LD) or constant light (LL) postnatally and exposed to ( $A, B$ ) LD and (C, D) LL environments in adulthood. 